\title{
Avaliação da Atividade Bacteriostática de Carvão Ativado Impregnado com Prata Frente à Bactéria Pseudomonas aeruginosa.
}

\author{
Lorena F. S. Oliveira, Letícia K. Sebastiany, Plínio L. F. Naves \& \\ José D. R. de Campos
}

A Pseudomonas aeruginosa é um microrganismo comumente presente em efluentes de origem hospitalar, pois é um patógeno nosocomial, causador de infecções de difícil tratamento. A prata possui propriedades antimicrobianas conhecidas, sendo empregada juntamente com carvão ativado em filtros domésticos. Foram portanto, desenvolvidos filtros com amostras de carvão ativado de casca de coco de dendê (Elaeis guineensis) impregnadas com prata, que posteriormente filtraram soluções contendo o microrganismo de estudo. Após incubação, as colônias foram contadas e determinadas (UFC/mL), revelando que a amostra com maior concentração do metal melhor inibiu o crescimento da bactéria, apresentando atividade bacteriostática, e confirmando seu papel fundamental.

Palavras-chave: microrganismo; carvão ativado; prata.

Pseudomonas aeruginosa is a microorganism commonly present in effluents of hospital origin, since it is a nosocomial pathogen, which causes difficult to treat infections. The silver has known antimicrobial properties, being used together with activated charcoal in domestic filters. Therefore, filters were developed with silver impregnated palm coconut shells (Elaeis guineensis), which subsequently filtered solutions containing the study microorganism. After incubation, the colonies were counted and determined (CFU / $\mathrm{mL}$ ), revealing that the sample with the highest concentration of the metal better inhibited the growth of the bacterium, presenting bacteriostatic activity, and confirming its fundamental role.

Keywords: microorganism; activated carbon; silver. 


\section{Introdução}

A água é o recurso natural mais abundante da Terra, e de extrema importância para todas as formas de vida, devido à sua larga utilização seja no uso doméstico, na agricultura, indústria e agropecuária. Contudo, a água atua como um veículo de transmissão de diversas doenças, devido à presença de inúmeros contaminantes, como: vírus, bactérias, parasitas, toxinas, produtos químicos e metais tóxicos que provêm de lixos domésticos, hospitalares e industriais. Esses contaminantes estão presentes, devido a tratamentos ineficazes nos efluentes aquosos ou a falta deles ${ }^{1}$.

Para consumo humano, a legislação brasileira diz que a água deve estar de acordo com a Portaria 2914/2011 do Ministério da Saúde $^{2}$ que dita os padrões de potabilidade da água, com os níveis máximos de contaminantes que a água deve ter para ser considerada própria para o consumo humano. Embora a água fornecida pelas Estações de Tratamento de Água (ETA) esteja dentro dos parâmetros de qualidade da legislação, no trajeto ETA-ponto de uso, ou no armazenamento da água nas residências (caixa d'água), pode-se contaminar a água antes de ela ser consumida. Para melhorar ainda mais a qualidade da água, faz-se o uso de filtros domésticos. No entanto, é comum a formação de colônias de microrganismos, sua proliferação e a formação de biofilmes nesses filtros, o que, na maioria das vezes, interfere no seu funcionamento e pode levar à diminuição da vida útil dos equipamentos ${ }^{3}$. O crescimento de microrganismos em alimentos, embalagens e outros produtos levou pesquisadores a estudar e desenvolver produtos inovadores com propriedades antimicrobianas. Dentro dessa gama de produtos, está envolvido o carvão ativado impregnado com prata ${ }^{4}$.

\section{FILTROS DOMÉSTICOS DE CARVÃO ATIVADO}

Para elevar a qualidade da água a ser consumida, é comum fazer o emprego de filtros domésticos. Há vários no mercado, os quais geralmente são constituídos de cartuchos de porcelana porosa ou materiais semelhantes, com ou sem carvão ativado, sendo que alguns ainda possuem prata aderida. A porcelana porosa dos cartuchos é responsável pela retenção de partículas em suspensão, as maiores causadoras da turbidez das águas e o carvão ativado tem como objetivo corrigir o odor e sabor do fluido, bem como remover cloro residual e compostos orgânicos ${ }^{5}$. Nesse processo, a matéria orgânica fica aderida ao filtro. Há alguns filtros que possuem sistema de retrolavagem para limpeza interna desses, injetando água no sentido oposto ao de saída com uma determinada pressão. Contudo, esse processo não assegura a pureza da água filtrada por esses equipamentos, podendo a matéria orgânica retida no filtro servir de alimento para microrganismos se desenvolverem formando biofilme $e^{6,7}$.

\section{BIOFILMES BACTERIANOS}

Os biofilmes são comunidades de microrganismos que se desenvolvem em uma matriz polimérica extracelular, semelhantes a um gel. As células microbianas aderem-se a uma superfície sólida e multiplicam-se secretando uma substância polimérica constituída de macromoléculas ${ }^{8}$.

Para o crescimento desses organismos, é necessária a presença de alguns nutrientes, como nitrogênio, enxofre e carbono. Os biofilmes podem apresentar-se em espessuras variáveis, que vão de micrômetros até centímetros. Sua composição também pode ser variável, mas a água representa a maior porcentagem. Há ainda a presença dos microrganismos, polissacarídeos, matéria orgânica e outras substâncias dissolvidas e adsorvidas ${ }^{9,8}$.

\section{PSEUDOMONAS AERUGINOSA}

A Pseudomonas aeruginosa é um bacilo, Gram-negativo, aeróbio, pertencente à família Pseudomonadaceae. É um microrganismo móvel, pois possui um ou mais flagelos que são usados para sua locomoção ${ }^{10}$. É um patógeno, causador de infecções em diversos sítios do corpo humano, como pneumonias, infecções urinárias, infecção de feridas cirúrgicas e na corrente sanguínea, pois consegue desenvolver resistência a diversos antibióticos. Sua presença nos recursos hídricos pode ser resultado de despejos de resíduos hospitalares nos cursos de água e a falta de tratamento adequado dos efluentes ${ }^{11}$. 
Essa bactéria foi escolhida para o estudo, pois é dentro do grupo das Pseudomonas a de maior relevância ${ }^{11}$, e por ser um dos microrganismos de ensaios de desempenho da eficiência bacteriológica da norma ABNT NBR 15176:2004 $(\text { INMETRO) })^{12}$.

\section{MECANISMO DE AÇÃO ANTIMICROBIANA DA PRATA IÔNICA E METÁLICA}

Os mecanismos da ação antimicrobiana da prata ainda não são totalmente compreendidos e definidos, por isso, estão sendo investigados. Entretanto, alguns mecanismos propõem atividades para íons prata, como ligação extracelular e precipitação da prata na membrana, pois a parede celular dos microrganismos é composta de peptideoglicano, sua carga negativa interage com a carga positiva dos íons prata, e a partir daí, a prata pode então se ligar em grupos proteicos e enzimas levando à inativação dessas ${ }^{13}$. Outras duas formas de interação na forma iônica são: interferindo na funcionalidade do DNA (Ácido desoxirribonucleico) e RNA (Ácido ribonucleico), e modificando a membrana plasmática da célula ${ }^{14}$.

Já para o efeito antibacteriano de nanometais, há duas possibilidades: (1) a toxicidade do íon metálico livre resultante da dissolução de superfície das nanopartículas e (2) estresse oxidativo via geração de espécies reativas de oxigênio (EROs) nas superfícies das nanopartículas. Dessa forma, fica difícil para as células das bactérias desenvolverem resistência a esses antimicrobianos ${ }^{15}$.

Kora e Arunachalam ${ }^{16}$ estudando sobre a atividade antibacteriana de nanopartículas de prata realizaram testes com a bactéria $P$. aeruginosa. O teste consistiu em usar a bactéria e descobrir o possível envolvimento de radicais livres na atividade antibacteriana. Para tanto, foram adicionadas nanopartículas de prata com concentração de 4 $\mu \mathrm{g} / \mathrm{mL}$, e ainda soluções de N-acetilcisteína (NAC) e ácido ascórbico (AA) na concentração de $10 \mathrm{mM}$ em placas com Ágar Mueller-Hinton, as placas foram inoculadas com 230 UFC de $P$. aeruginosa e incubadas a $37^{\circ} \mathrm{C}$ por $18 \mathrm{~h}$. Após esse período, as bactérias sobreviventes foram contadas. Placas controle com e sem antioxidantes foram preparadas para averiguação.
Os antioxidantes foram usados com o objetivo de eliminar as espécies reativas de oxigênio produzidas pelas nanopartículas de prata. $\mathrm{Na}$ placa controle sem nanopartículas e sem antioxidantes, as colônias bacterianas foram claramente observadas, a placa controle contendo o NAC não apresentou inibição do crescimento. Contudo, a placa contendo o AA mostrou uma pequena redução no número de colônias. A placa com nanopartículas de prata sem antioxidantes mostrou que a inibição das colônias foi completa. Nas placas com nanopartículas de prata com o NAC, as colônias de bactérias estavam presentes ainda que em menor número e as placas com AA e nanopartículas revelaram que o antioxidante foi capaz de proteger todas as células bacterianas ( $100 \%$ de sobrevivência) da atividade da prata. Esses resultados propõem que, provavelmente, essas espécies reativas de oxigênio (ROS) estejam envolvidas na atividade bactericida de nanopartículas de prata e que o AA impediu essa atividade, por isso, todas as células bacterianas resistiram ${ }^{16}$.

\section{Metodologia}

Caracterização do carvão ativo por determinação do número de iodo

A amostra de carvão ativado sem prata foi pulverizada, acrescida de solução de ácido clorídrico $5 \%$ e solução de iodo $0,100 \mathrm{~N}$ e pelo método ASTM D4607-9417 determinou-se o número de iodo.

\section{IMPREGNAÇÃO DA PRATA NO CARVÃO}

As amostras foram preparadas adicionando às massas de carvão ativado, solução preparada com nitrato de prata da Vetec (pureza 99,8\%). A impregnação de prata na estrutura do carvão ativado foi obtida por meio de agitação até a evaporação do líquido, conforme o método de Mitsumori, Takeda e Miyasaco ${ }^{18}$. As concentrações das amostras foram escolhidas com base na concentração de prata usada nos filtros comerciais que é de $0,08 \%$. Foram preparadas, portanto, amostras com concentrações menores e maiores em torno deste valor.

Para caracterização morfológica e identificação dos elementos químicos na amostra de carvão sem metal, foi 
utilizada a técnica de microscopia eletrônica de varredura (MEV), com microanálises de raios-X. A amostra foi recoberta com filme de carbono condutor (grafite), colocadas em suporte de alumínio e analisadas no MEV Jeol JSM-6610, equipado com EDS, Thermo Scientific NSS Spectral Imaging. A análise foi realizada no Laboratório Multiusuário de Microscopia de Alta Resolução na Universidade Federal de Goiás.

\section{ENSAIO DE CRESCIMENTO DO BIOFILME}

Uma cepa de $P$. aeruginosa ATCC (American Type Culture Collection) 9027, do Laboratório de Microbiologia da Universidade Estadual de Goiás foi inoculada em meio sólido (Ágar cetrimida) e incubada a $37{ }^{\circ} \mathrm{C}$ por $24 \mathrm{~h}$. Colônias de $P$. aeruginosa foram transferidas para $10 \mathrm{~mL}$ de água peptonada e ajustou-se a turvação à escala 0.5 McFarland (1,5 x 108 UFC (Unidade de Formação de Colônias) $/ \mathrm{mL}$ ). Foi utilizado o método de diluição seriada até a 105 diluição e a solução foi incubada a $37^{\circ} \mathrm{C}$ por 16 $18 \mathrm{~h}$ em estufa de cultura modelo $002 \mathrm{CB}$ da FANEM.

\section{DESENVOLVIMENTO DOS FILTROS}

Em câmara de fluxo laminar, foram montados sistemas de filtros de carvão, ativados segundo a ABNT NBR 15176/04 12 com modificações. Em seringas de $60 \mathrm{~mL}$ foram adicionados 5 gramas de carvão ativado (sem e com prata impregnada), autoclavados a $120^{\circ} \mathrm{C}$ por 20 minutos. Pelos leitos filtrantes, passaram $50 \mathrm{~mL}$ da água de prova contendo a bactéria Pseudomonas aeruginosa e os filtros foram levados à estufa a $37^{\circ} \mathrm{C}$ por 5 dias. Após o período de incubação, a massa do carvão ativado foi retirada e transferida para solução fisiológica. A solução foi colocada em ultrassom de $25 \mathrm{~Hz}$ da MaxiClean 1450 para desprendimento das colônias, realizando em seguida diluições seriadas para o método de contagem de placa (UFC/mL).

\section{Resultados e Discussão}

\section{Caracterização do carvão ativo por determinação do número de iodo}

O número de iodo é um indicador de porosidade relativa do carvão ativado, e não necessariamente mostra a capacidade do carvão ativado em adsorver outras espécies. O número de iodo pode ser usado como uma aproximação da área de superfície para alguns tipos de carvões. Entretanto, qualquer relação entre a área de superfície e o número de iodo não pode ser generalizada, pois ela varia conforme as alterações do material, matéria-prima, condições de processamento e distribuição dos poros.

O carvão ativado da casca de dendê (Elaeis guineensis) mostrou uma grande área superficial, com número de iodo de $1456 \mathrm{mg} \cdot \mathrm{g}^{-1}$, sendo que Sebastiany ${ }^{19}$ encontrou valores próximos para o mesmo tipo de carvão ativado com número de iodo igual a $1420 \mathrm{mg} \cdot \mathrm{g}^{-1}$. Loureiro ${ }^{20}$ também determinou o número de iodo de quatro amostras de carvão ativado de casca de coco, o número de iodo das amostras variaram entre 654,51 a 465,53 $\mathrm{mg} \cdot \mathrm{g}^{-1}$, sendo que o limite mínimo de uso para aplicações em filtros é de 600 mg.g ${ }^{-1}$ segundo a ABNT NBR 12073:199121.

\section{Microscopia eletrônica de varredura (MEV) acoplada ao espectrômetro de energia dispersiva (EDS)}

A fim de se obterem informações sobre a morfologia e identificação de elementos químicos presentes no carvão, suas características microestruturais foram analisadas por MEV acoplada ao EDS, revelando uma composição química elementar aproximada.

A Figura 1 representa as imagens obtidas através da microscopia eletrônica de varredura do carvão ativado de casca de coco de dendê (Elaeis guineensis), com imagens retroespalhadas que permitem analisar a composição.

De acordo com a Figura 1, sugere-se que a estrutura carbonácea apresenta buracos na superfície deste material. As variações de tons demonstram composição diferente de elementos químicos. A diferença de composição é devido à diferença de número atômico $(Z)$. Os pontos mais claros indicam elementos com $\mathrm{Z}$ maiores.

Ainda para esta imagem, fez-se também a análise por EDS (Figura 2), em que se pode verificar uma quantificação elementar pontual média que relata a existência de alguns elementos presentes na amostra analisada.

Com base na Figura 2, pode-se afirmar que a amostra de carvão ativado é constituída basicamente por carbono, oxigênio, silicato e minerais. 


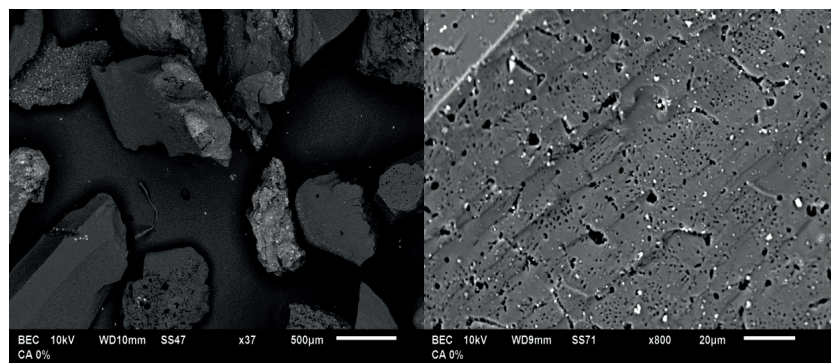

Figura 1. Imagem obtida do carvão ativado de casca de coco de dendê (Elaeis guineensis) pelo MEV em um aumento de x37 e x800.

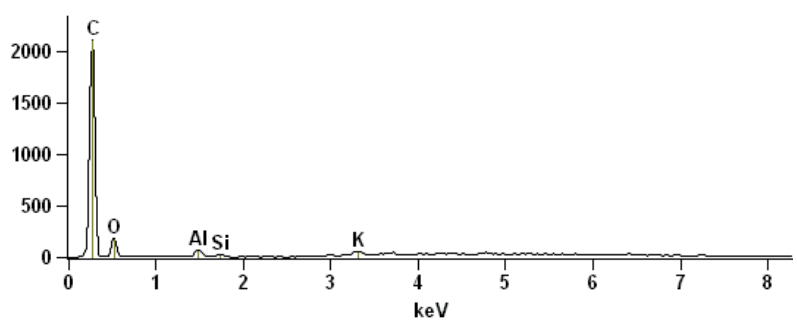

Figura 2. Espectro da análise da energia dispersiva (EDS) da amostra de carvão ativado de casca de coco de dendê (Elaeis guineensis).

\section{QUANTIFICAÇÃO DE METAIS IMPREGNADOS DO CARVÃO ATIVADO}

O objetivo da impregnação era obter amostras de carvão ativado com prata nas concentrações de $0,025 \%, 0,1 \%$ e $0,25 \%$. Para avaliar o processo de impregnação e quantificar o metal, foram preparados padrões e construiu-se uma curva de calibração (Figura 3). Os resultados das porcentagens de prata teórica e experimental estão na Tabela 1.

A faixa para a curva foi escolhida com base na janela de concentração das amostras que variaram de $0,025 \%$ a $0,25 \%$, o que equivale a uma variação de 25 a $250 \mathrm{mg} / \mathrm{L}$. A partir das diluições utilizadas, a curva de calibração construída apresentou coeficiente de correlação de 0,99916 .

Os resultados mostraram que as porcentagens de prata impregnadas nas amostras apresentaram algumas poucas variações em relação às concentrações teóricas e coeficiente de correlação próximo de 1 . O valor mais distante da concentração teórica é da amostra de $0,0295 \%$ que pode ser devido à análise de uma amostra com impregnação de prata não homogênea na superfície do carvão ativado. Entretanto, os resultados foram satisfatórios, mostrando concentrações reais de prata nas amostras.

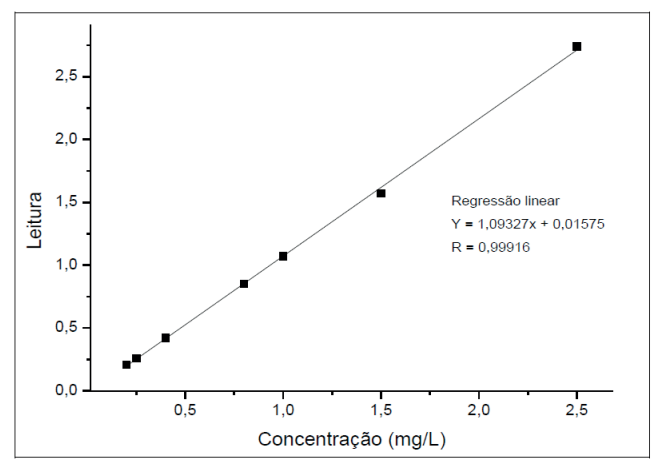

Figura 3. Curva de calibração para quantificação de prata impregnada nas amostras de carvão.

Tabela 1. Porcentagem de prata teórica, experimental e desvio padrão.

\begin{tabular}{|c|c|c|}
\hline \% de Ag teórica & $\begin{array}{c}\text { \% de Ag } \\
\text { Experimental }\end{array}$ & Desvio padrão ( $\boldsymbol{\sigma})$ \\
\hline 0,025 & 0,0295 & 0,0010 \\
\hline 0,100 & 0,0845 & 0,0014 \\
\hline 0,250 & 0,2214 & 0,0014 \\
\hline
\end{tabular}

\section{ENSAIOS DE CRESCIMENTO DE BIOFILME}

Foram construídos dois filtros para cada amostra de carvão. Para melhor análise dos resultados da contagem das UFC da $P$. aeruginosa nas amostras, foi construída a Tabela 2 e o Gráfico 1.

Tabela 2. Resultado da contagem de UFC/mL das amostras de carvões ativados sem prata (CA $0 \% \mathrm{~m} / \mathrm{m})$ e impregnados com prata $(\% \mathrm{~m} / \mathrm{m})$.

\begin{tabular}{|c|c|}
\hline Amostra (\% de Ag) & UFC/mL \\
\hline 0 & $>3,0 \times 107$ \\
\hline 0,0295 & $>1,5 \times 106$ \\
\hline 0,0845 & $6,8 \times 105$ \\
\hline 0,2214 & $1,9 \times 105$ \\
\hline
\end{tabular}


O número de colônias na solução da água de prova usada na filtração, foi determinada e apresentou contagem de 2,0x108 UFC/mL, que quando comparada a contagem de 3,0x107 no filtro com carvão ativado sem prata já mostra uma diminuição de $1 \mathrm{Log}$. Ao se analisar os resultados das amostras de carvão quando se compara os valores dos carvões sem prata e com prata, há uma diferença de 1 log para o carvão $0,0295 \%$ e de $2 \log$ para as demais amostras.

Sebastiany $^{19}$ avaliou o efeito antimicrobiano do carvão ativado da casca de coco de dendê impregnado com $0,0280 \%$ e $0,0662 \%(\mathrm{~m} / \mathrm{m})$ de prata, frente à mesma bactéria, e verificou contagem de 1,6×104 UFC/mL para a menor concentração do metal e 2,8x105 UFC/mL para a maior, sugerindo que o tempo de filtração teve implicação fundamental na contagem das colônias, já que no filtro contendo a maior concentração do metal, apresentou maior tempo de filtração e consequentemente quantidade de colônias superior. Entretanto alude-se que os resultados não apresentaram diferenças significativas e uma concentração de prata ótima para trabalho.

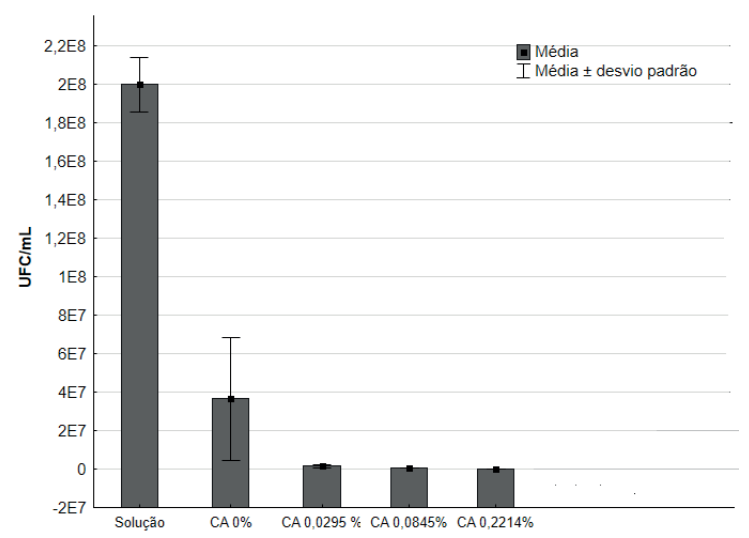

Gráfico 1. Resultados da contagem das UFC/mL da água de prova e dos filtros com carvões ativados sem e com prata impregnada.

Conforme análise do Gráfico 1, verifica-se que as colônias da bactéria $P$. aeruginosa diminuíram com o aumento da concentração de prata. Essa observação está em acordo com o estudo de Kora e Arunachalam ${ }^{16}$ com nanopartículas de prata, onde é evidenciado que a atividade bactericida das nanopartículas do metal dependem tanto da sua concentração quanto do número de bactérias iniciais. A prata impregnada mostrou potencial atividade bactericiostática devido ao resultado linear nas amostras com diferentes concentrações, conservando o mesmo log e inibindo o desenvolvimento da $P$. aeruginosa reforçando que o uso da prata tem um papel fundamental em filtros domésticos.

Ribeiro $^{22}$ preparou carvões ativados impregnados com íons prata em diferentes concentrações e por métodos variados, realizando posteriormente testes para avaliar a ação antimicrobiana frente aos microrganismos Staphylococcus aureus e Escherichia coli pelo método de difusão direta. Os resultados confirmaram que a prata é um importante agente antibacteriano, indicando versatilidade para outras cepas que não a $P$. aeruginosa.

\section{Conclusão}

O carvão ativado da casca de coco de dendê (Elaeis guineensis) apresentou uma porosidade alta, considerando o resultado da análise de número de iodo, mostrando grande área superficial e presença de minerais solúveis. Sugere-se que a prata impregnada no carvão ativado se encontra na forma metálica, mostrando atividade bacteriostática, ao diminuir o número de colônias de >3,0x107 para 1,9x105 $\mathrm{UFC} / \mathrm{mL}$ da bactéria Pseudomonas aeruginosa, detendo seu crescimento e dificultando a sua proliferação.

\section{Agradecimentos}

Os autores agradecem a agência de fomento à pesquisa de Coordenação de Aperfeiçoamento de Pessoal de Nível Superior (CAPES) pelo apoio financeiro para a realização desse trabalho.

\section{Referências}

1. Pereira, W. S., Freire R. S. Ferro zero: uma nova abordagem para o tratamento de águas contaminadas com compostos orgânicos poluentes. Química Nova, vol. 28, 2005. 
2. BRASIL, Ministério da Saúde. Portaria n. ${ }^{\circ}$ 2.914, de 12 de Dezembro de 2011. Dispõe sobre normas de potabilidade de água para o consumo humano. Brasília: SVS, 2011.

3. Velten, S.; Boller, M.; Köster, O.; Helbing, J.; Weilenmann, H-U.; Hammes, F. Development of biomass in a drinking water granular active carbon (GAC) filter. Water research, vol 45, p. 6347-6354, 2011.

4. Islam, M. M.; Masum, S. M.; Mahbub, K. R.; Haque, M. Z. Antibacterial Activity of Crab-Chitosan against and Escherichia coli. Journal of Advanced Scientific Research. p. 63-66, 2011.

5. Pedro, N. A. R.; Brigido, B. M.; Badolato, M. I. C.; ANTUNES, J. L. F.; OLIVEIRA, E. Avaliação de Filtros Domésticos Comerciais para purificação de Águas e Retenção de Contaminantes Inorgânicos. Química Nova, vol. 20, n², p.208-212, Março/Abril, 1997.

6. Guerra, N. M. M., Otenio, M. H.; Silva, M. E. Z.; Guilhermetti, M.; Nakamura, C. V.;Ueda-Nakamura, T.; DIAS FILHO, B.P. Ocorrência de Pseudomonas aeruginosa em água potável. Red de Revistas Científicas de América Latina, el Caribe, España y Portugal. Maringá, vol. 28, n. 1, p. 13-18, Janeiro/Março, 2006.

7. Cavassin, E. D.; Belei, R. A.; Pachenski, L. R.; Oliveira, C. H.; Carrilho, C. M. D.; Perugini, M. R. E. Análise microbiológica de água filtrada por filtros domésticos em ambiente hospitalar. Semina: Cio Biol. Saúde, Londrina, vol. 20/21, n. 2, p. 49-56, jun. 1999/2000.

8. Chaves, L. C. D. Estudo da Cinética de Formação de Biofilmes em Superfícies em Contacto com Água Potável. Dissertação (Mestrado em Tecnologia do Ambiente), Departamento de Engenharia Biológica, Universidade do Minho, 2004.

9. Xavier, J. B; Picioreanu, C.; Almeida, J. S.; Van Loosdrecht, M. C. M. Monitorização e modelação da estrutura de biofilmes. Biomatemática - Modelação da estrutura de Biofilmes (Boletim de Biotecnologia), no. 76, p.2-13, 2003.

10. Ferreira, J. A. B. Diversidade genética, perfil de resistência aos antimicrobianos e produção de biofilmes de amostras de Pseudomonas aeruginosa isoladas da água utilizada em unidades de terapia renal substitutiva. Dissertação de mestrado, Rio de Janeiro, 2009.

11. Paviani, E. R.; Stadinik, C. B.; Heinek, I. Estudo da Epidemiologia e Perfil de Sensibilidade da Pseudomonas aeruginosa. Infarma, vol. 15, 11-12, Novembro/Dezembro, 2003 - Janeiro/2004.

12. ASSOCIAÇÃO BRASILEIRA DE NORMAS TÉCNICAS. Aparelho para melhoria da qualidade de água de uso doméstico Aparelho por gravidade. NBR 15176: Rio de Janeiro, 2004.

13. Araujo, E. A. Caracterização físico-química e ação antimicrobiana de nanopartículas de prata obtidas por uma nova síntese. Tese (Doutorado), Universidade Federal de Viçosa, Viçosa-MG, 2010.

14. Clemo, B. Ultra-Fresh Silpure A nova geração antimicrobiana baseada na nanotecnologia da prata. Química Têxtil, n.80, p. 14-18, setembro, 2005.

15. Dizaj, S.m.; Lotfipour, F. Barzegar-Jalali, M.; Zarrintan, M.h.; Adibkia, K. Antimicrobial activity of the metals and metal oxide nanoparticles. Materials Science and Engineering C, v. 44, 2014. p.278-279.

16. Kora, A. J.; Arunachalam, J. Assessment of antibacterial activity of silver nanoparticles on Pseudomonas aeruginosa and its mechanism of action. World J Microbiol Biotechnol 27, p.1209-1216, 2011.
17. Astm D 4607 - 94; Standard Test Method for Determination of Iodine Number of Activated Carbon; (Reapproved 1999).

18. Mitsumori, N.; Takeda, C.; Miyasaco, H. Nippon Shinyaku Company, Limited (Kyoto, JAPAN). Method of treating silver impregnated activated carbon. United States Patent US 4045553 1977.

19. Sebastiany, L. K. Atividade antimicrobiana de carvão ativado impregnado com prata. Trabalho de conclusão de curso, Universidade Estadual de Goiás, 2013.

20. Loureiro, L. F. Avaliação de adsorção do herbicida 2,4-D em carvão ativado em pó e granular por meio de análises de isotermas de adsorção utilizando diferentes qualidades de água. Dissertação (Mestrado), Universidade Federal do Espírito Santo, Vitória-ES, 2012

21. ASSOCIAÇÃO BRASILEIRA DE NORMAS TÉCNICAS. Carvão ativado pulverizado - Determinação do número de iodo - Método de ensaio. NBR 12073: Rio de Janeiro, 1991.

22. Ribeiro, G.v. Obtenção de Carvão Ativado Impregnado com Prata para Fins Bactericidas. Dissertação (Mestrado), Universidade de Santa Maria, 2014.

\section{Lorena F. de Souza ${ }^{1 *}$, Letícia K. Sebastiany ${ }^{3}$, Plínio L. F. Naves ${ }^{2}$ \& José D. R. Campos².}

\author{
${ }^{1}$ Faculdade de Tecnologia SENAI Roberto Mange, \\ CEP 75113-630, \\ Anápolis, GO, Brasil \\ ${ }^{2}$ Unidade Universitária de Ciências Exatas e \\ Tecnológicas, UEG, CP 459, CEP 75001-970, \\ Anápolis, GO, Brasil \\ ${ }^{3}$ Universidade Federal de São Carlos (UFSCar), Rod. \\ Washington Luís Km 235- SP-310, CEP 13565-905, \\ São Carlos, SP, Brasil
}

\section{*E-mail: lorena99390262@hotmail.com}


